\title{
Outcomes from intracerebral hemorrhage among patients pre-treated with statins
}

\author{
Flávio Ramalho Romero', Eduardo de Freitas Bertolini², \\ Vanessa Nogueira Veloso ${ }^{3}$, Leandro Venturini ${ }^{4}$, Eberval G. Figueiredo ${ }^{5}$
}

\begin{abstract}
Objective: 3-hydroxy-3-methylglutaryl coenzyme A (HMG-CoA) reductase inhibitors, or statins, have been associated with improved clinical outcomes after ischemic stroke and subarachnoid hemorrhage, but with an increased risk of incidental spontaneous intracerebral hemorrhage $(\mathrm{ICH})$. We investigated whether the statin use before $\mathrm{ICH}$, was associated with functional independence, 90 days after treatment. Method: We analyzed 124 consecutive ICH patients with 90-day outcome data who were enrolled in a prospective cohort study between 2006 and 2009. Eighty-three patients were included in this study. Among ICH survivors, univariate Cox regression models and Kaplan-Meier plots were used to determine subject characteristics that were associated with an increased risk of recurrence. Statin usage was determined through interviewing the patient at the time of $\mathrm{ICH}$ and confirmed by reviewing their medical records. Independent status was defined as Glasgow Outcome Scale grades 4 or 5. Results: Were stain users 20/83 (24\%) patients before the $\mathrm{ICH}$. There was no effect from pre-ICH statin use on the functional independence rates ( $32 \%$ versus $36 \%, P=0.79$ ) or mortality ( $41 \%$ versus $47 \%, P=0.82$ ). Conclusion: Pre-ICH statin use is not associated with changes to $\mathrm{ICH}$ functional outcome or mortality. Key words: cerebral hemorrhage, hydroxymethylglutaryl-CoA reductase inhibitors.
\end{abstract}

Prognóstico da hemorragia intracerebral em pacientes previamente tratados com estatinas

\section{RESUMO}

Objetivo: Inibidores da 3-hydroxy-3-methylglutaryl coenzima A (HMG-CoA) redutase, ou estatinas, têm sido associados com melhora do prognóstico após eventos encefálicos isquêmicos e hemorragia subaracnóidea, mas com um aumento do risco de evento encefálico hemorrágico (AVEh). Nós investigamos se o uso de estatinas prévio ao sangramento é associado com independência funcional em 90 dias. Método: Analisamos 124 pacientes consecutivos com AVEh com 90 dias de seguimento, selecionando 83 para um estudo coorte prospectivo entre 2006 e 2009. O uso de estatinas foi determinado pela entrevista ao paciente no momento da entrada ao hospital e complementado pela revisão do prontuário. Foi definido como independência funcional um GOS (Glasgow Outcome Scale) 4 ou 5. Resultados: Estatinas eram usadas por 20/83 (24\%) antes do AVEh. Não houve efeito benéfico do uso prévio ao AVEh de estatinas nas taxas de independência funcional ( $32 \%$ versus $36 \%, P=0,79$ ) ou mortalidade ( $41 \%$ versus $47 \%, P=0,82)$. Conclusão:

\section{Correspondence}

Flávio Ramalho Romero Rua Pascoal Vita 366 / 94 05445-000 São Paulo SP - Brazil E-mail: frromero@ig.com.br romeroncr@gmail.com

Received 12 July 2010

Received in final form 4 January 2011 Received in final form 11 January 2011
O uso de estatina pré-AVEh não é associado com melhora do prognóstico funcional ou taxa de mortalidade.

Palavras-chave: hemorragia cerebral, inibidores de hidroximetilglutaril-CoA redutases.

Neurosurgery Service, Hospital Ipiranga - SUS, São Paulo SP, Brazil: 'Neurosurgeon at Hospital Ipiranga - SUS, Hospital São Camilo, São Paulo SP, Brazil, and Hospital São Luiz, São Paulo SP, Brazil. Postgraduate Student in Neurosurgery Division, University of São Paulo, São Paulo SP, Brazil; ${ }^{2}$ Neurosurgeon at Hospital Ipiranga - SUS; ${ }^{3}$ Resident in Internal Medicine at Hospital Ipiranga - SUS; ${ }^{4} \mathrm{Head}$ of Neurosurgery Division, Hospital Ipiranga - SUS; ${ }^{5} \mathrm{Head}$ of Neurovascular Group, Neurosurgery Division, Hospital das Clínicas, School of Medicine, University of São Paulo, São Paulo SP, Brazil. 
Intracerebral hemorrhage $(\mathrm{ICH})$ causes first-time stroke in $10 \%$ to $15 \%$ of such patients, with a 30 -day mortality rate of $35 \%$ to $52 \%$; half of the deaths occur in the first two days ${ }^{1-3}$. In one population study on 1041 cases of ICH, $50 \%$ had a deep location, $35 \%$ were lobar, $10 \%$ were cerebellar and $6 \%$ were in the brain stem ${ }^{4}$. The mortality rate one year after $\mathrm{ICH}$ varies according to the location of the ICH: $51 \%$ for deep hemorrhage, $57 \%$ for lobar, $42 \%$ for cerebellar and $65 \%$ for brain stem ${ }^{5}$. Out of the estimated 67,000 patients who had an ICH in the United States during 2002, only $20 \%$ are expected to be functionally independent six months later ${ }^{3}$.

3-hydroxy-3-methylglutaryl coenzyme A (HMG$\mathrm{CoA}$ ) reductase inhibitors, or statins, have other effects in addition to decreasing cholesterol synthesis ${ }^{6}$. Statintreated animals have better outcomes in experimental models for ischemic stroke ${ }^{7}$ and intracerebral hemorrhage $(\mathrm{ICH})^{8,9}$. Human studies suggest that statins are associated with better outcomes after ischemic stroke $\mathrm{e}^{10}$ and subarachnoid hemorrhage ${ }^{11}$.

In contrast, it is not known whether pre-ICH statin use confers better outcomes among patients with $\mathrm{ICH}$. Some of the pleiotropic effects of statins, such as decreased platelet aggregation ${ }^{12}$ and decreased thrombogenesis $^{13}$, may promote hematoma expansion or increase the risk of recurrent hemorrhage.

Therefore, we investigated whether prior use of statin would improve the outcome among patients with $\mathrm{ICH}$.

\section{METHOD}

We retrospectively analyzed data from an ongoing single-center prospective longitudinal cohort study on primary ICH. All patients with a baseline admission CT scan and determination of functional status at 90 days were eligible. Clinical information, including medication use and dosage, was abstracted from the medical records and supplemented by interview. $\mathrm{ICH}$ volume and location were determined by means of computerassisted segmentation. This study was approved by the local ethics committee.

There were 124 consecutive admissions with symptom onset between January 1, 2006 and December 31,2010 . Baseline CT scan was not performed or was missing in 8/124 (0.6\%), and other data were missing in 5/124 (0.4\%), leaving 111 subjects with complete baseline information. Death within 30 days occurred in 28/111, thus leaving 83/111 30-day survivors. Therefore, 90 -day Glasgow outcome scale (GOS) was determined for a total of 83/124 potential subjects (67\%).

Independent status was defined as GOS 4 or 5 . Logistic regression models were constructed to determine whether pre-ICH statin use was associated with independent status or mortality. Age and Glasgow coma
Table. Some data from the patients according to presence of statin use before $\mathrm{ICH}$.

\begin{tabular}{lccc}
\hline Characteristic & $\begin{array}{c}\text { Statin } \mathbf{n = 2 0} \\
(\mathbf{2 4 \% )}\end{array}$ & $\begin{array}{c}\text { No statin } \\
\mathbf{n = 6 3 ( 7 6 \% )}\end{array}$ & $\mathbf{P}$ \\
\hline Median age (SD) & $68(8.2)$ & $69(7.6)$ & 0.73 \\
GCS (variation) & $11(6-15)$ & $12(6-15)$ & 0.89 \\
GOS 4 or 5 & $32 \%$ & $36 \%$ & 0.79 \\
(90-day independence) & & & \\
90-day mortality & $41 \%$ & $47 \%$ & 0.82 \\
\hline GCS: Glasgow coma scale; GOS: Glasgow outcome scale.
\end{tabular}

score (GCS) score were categorized according to cutoff points that were established in univariate analysis, as follows: [1] age: $<69,70$ to 79 and $>80$, [2] GCS: 3 to 10,11 to 14 and 15 .

Among the ICH survivors, univariate Cox regression models and Kaplan-Meier plots were used to determine subject characteristics that were associated with an increased risk of recurrence. Post-ICH statin use was analyzed as a time-dependent variable because some subjects started or discontinued statins during the follow-up period. Post-ICH statin use and any variables associated with ICH recurrence $(\mathrm{P}<0.20)$ were entered into a multivariable Cox regression model, followed by backward elimination of nonsignificant variables $(P>0.05)$. Statistical analyses were performed using SAS version 9.1.3.

\section{RESULTS}

Were statin users 20/83 (24\%) patients before the $\mathrm{ICH}$. There was no effect from pre-ICH statin use on the functional independence rates ( $32 \%$ versus $36 \%, \mathrm{P}=0.79$ ) or mortality ( $41 \%$ versus $47 \%, \mathrm{P}=0.82$ ). Medical comorbidities and warfarin use were more common in statin users. The multivariable-adjusted odds ratio for independent status in pre-ICH statin users was 1.03 (95\% CI: 0.71 to $2.21, \mathrm{P}=0.71$ ).

Pre- $\mathrm{ICH}$ statin use was not associated with independent status or mortality (Table). We considered whether the effect of statin use might vary according to outcome definition or patient subgroups. There was no difference in 30-day or 90-day survival in pre- $\mathrm{ICH}$ statin users (data not shown). Because statin withdrawal may worsen stroke outcome ${ }^{14,15}$, we performed additional analyses after subtracting subjects among whom statins were discontinued $(\mathrm{n}=12)$ or adding subjects among whom statins were started $(n=15)$. However, the sample did not have enough power to allow definitive conclusions.

\section{DISCUSSION}

The initial experimental evidence generated from animals appeared in a couple of studies in 2004. In one 
of them, atorvastatin was administered orally beginning $24 \mathrm{~h}$ after ICH and was continued daily for one week. With a low dose of $2 \mathrm{mg} / \mathrm{kg}$, a significant reduction in neurological deficit two to four weeks after the ICH was observed, while a higher dose of $8 \mathrm{mg} / \mathrm{kg}$ did not improve functional outcome or reduce the brain damage ${ }^{14}$.

Supported by these studies, initial attempts to evaluate the effect on humans were made. In a retrospective study performed at Johns Hopkins Hospital, the effect of statin administered prior to ICH was assessed among 125 consecutive ICH patients. The authors found that patients with prior statin use had less perifocal edema than did those without prior statin use. The multivariate analysis showed a significant correlation between prior statin use and reduction of early absolute edema volume $^{15}$. The same group demonstrated that prior use of statins was associated with lower mortality at 30 days.

We did not detect any difference in outcomes among patients taking statins before $\mathrm{ICH}$, even after adjustment for medical comorbidities. In contrast, treatment with statins improved sensorimotor recovery in two animal models for $\mathrm{ICH}^{8,9}$. However, there may be biological differences between animals and humans regarding the type of injury that occurs after $\mathrm{ICH}$. In contrast to the animal studies, our subjects were taking various types and doses of statins. A recent study suggested that statins are associated with decreased 30-day mortality but not with improved functional outcome ${ }^{16,17}$. In our study, pre-ICH statin use had no effect on 30-day mortality. It is unclear whether the different results occurred because of the play of chance, or because of differences in the populations studied.

The main limitation of our study is that statin use was not randomly assigned, and therefore associations between statins and either $\mathrm{ICH}$ outcomes or recurrent $\mathrm{ICH}$ may be confounded with other factors that are associated with statin use, even though we adjusted for recognized confounders using regression models.

Our analysis of the dose-response effect of statins on ICH outcomes uses the simplistic assumption that maximum dose strengths are equipotent across different drugs.

These data come from a not-so-large series of consecutive ICH cases with functional outcome data and prospective follow-up and therefore provide a best estimate of the effect of statins on ICH outcomes in the absence of large trials. FitzMaurice calculated that a trial of statins to improve 90-day outcome should include 1026 subjects (randomized 1:1 to treat with statin or placebo), for it to get $90 \%$ power to detect an OR $>1.24$, for independent status in the statin $\operatorname{arm}^{18}$.

It is too early to come to any conclusion. In addition, because of the small sample size of the present study, and because the underlying prospective study does not define the statins that were used, no definitive conclusion can be drawn until a comprehensive, double blind, prospective study is performed.

\section{REFERENCES}

1. Broderick JP, Brott T, Tomsick T, Miller R, Huster G. Intracerebral hemorrhage more than twice as common as subarachnoid hemorrhage. J Neurosurg 1993;78:188-191.

2. Anderson CS, Chakera TM, Stewart-Wynne EG, Jamrozik KD. Spectrum of primary intracerebral haemorrhage in Perth, Western Australia, 1989-90: Incidence and outcome. J Neurol Neurosurg Psychiatry 1994;57:936-940.

3. Counsell C, Boonyakarnkul S, Dennis M, et al. Primary intracerebral haemorrhage in the Oxfordshire Community Stroke Project, 2: prognosis. Cerebrovasc Dis 1995;5:26-34

4. Flaherty ML, Woo D, Haverbusch M, et al. Racial variations in location and risk of intracerebral hemorrhage. Stroke 2005;36:934-937.

5. Flaherty $M L$, Haverbusch $M$, Sekar $P$, et al. Long-term mortality after intracerebral hemorrhage. Neurology 2006; 66:1182-1186.

6. Sacco RL, Liao JK. Drug insight: statins and stroke. Nat Clin Pract Cardiovasc Med 2005;2:576-584.

7. Endres M, Laufs U, Huang Z, et al. Stroke protection by 3-hydroxy-3methylglutaryl (HMG)-CoA reductase inhibitors mediated by endothelial nitric oxide synthase. Proc Natl Acad Sci U S A 1998;95:8880-8885.

8. Jung KH, Chu K, Jeong SW, et al. HMG-CoA reductase inhibitor, atorvastatin, promotes sensorimotor recovery, suppressing acute inflammatory reaction after experimental intracerebral hemorrhage. Stroke 2004;35:1744-1749.

9. Seyfried D, Han Y, Lu D, Chen J, Bydon A, Chopp M. Improvement in neurological outcome after administration of atorvastatin following experimental intracerebral hemorrhage in rats. J Neurosurg 2004;101:104-107.

10. Marti-Fabregas J, Gomis M, Arboix A, Aleu A, et al. Favorable outcome of ischemic stroke in patients pretreated with statins. Stroke 2004;35: 1117-1121.

11. Tseng MY, Hutchinson PJ, Czosnyka M, Richards H, Pickard JD, Kirkpatrick PJ. Effects of acute pravastatin treatment on intensity of rescue therapy, length of inpatient stay, and 6-month outcome in patients after aneurysmal subarachnoid hemorrhage. Stroke 2007;38:1545-1550.

12. Yokoyama S, Ikeda H, Haramaki N, Yasukawa H, Katoh A, Imaizumi T. HMG-CoA reductase inhibitor protects against in vivo arterial thrombosis by augmenting platelet-derived nitric oxide release in rats. J Cardiovasc Pharmacol 2005;45:375-381.

13. Asahi M, Huang $Z$, Thomas $S$, et al. Protective effects of statins involving both eNOS and tPA in focal cerebral ischemia. J Cereb Blood Flow Metab 2005;25:722-729.

14. Seyfried D, Han Y, Lu D, Chen J, Bydon A, Chopp M. Improvement in neurological outcome after administration of atorvastatin following experimental intracerebral hemorrhage in rats. J Neurosurg 2004;101:104-107.

15. Naval NS, Abdelhak TA, Urrunaga N, Zeballos P, Mirski MA, Carhuapoma JR. An association of prior statin use with decreased perihematomal edema. Neurocrit Care 2008 8:13-18.

16. McGirt MJ, Ambrossi GLG, Huang J, Tamargo RJ. Simvastatin for the prevention of symptomatic cerebral vasospasm following aneurysmal subarachnoid hemorrhage: a single-institution prospective cohort study Neurosurg 2009;110:968-974.

17. Blanco M, Nombela F, Castellanos M, et al. Statin treatment withdrawal in ischemic stroke: a controlled randomized study. Neurology 2007;69: 904-910.

18. FitzMaurice $E$, Wendell $L$, Snider R, et al. Effect of statins on intracerebral hemorrhage outcome and recurrence. Stroke 2008;39:2151-2154. 


\section{CORRECTIONS}

Correspondence: Flavio Ramalho Romero

Rua Pascoal Vita 366 / apto 94 - Vila madalena

05445-000 São Paulo SP - Brasil.

E-mail:frromero@ig.com.br/romeroncr@gmail.com

\section{Dear Editors,}

Ref.Article:Romero FR,BertoliniE, Velozo VN, Venturini L, Figueiredo EG. Outcomes from intracerebral hemorrhage among patients pretreated with statins. Arq Neuropsiquiatr 2011;69:452-454.

Some similar points have been observed between our paper and other by FitzMaurice et al. Effect of Statins on Intracerebral Hemorrhage Outcome and Recurrence. Stroke 2008; 39:2151-2154. These points are not coincidental but resulted from mistakes when the documents were selected and sent to the editor. So, instead of selecting my own results, I sent a file with graphic and words containing the data from the table of the Fitz Maurice's paper from which I intended to compare my data and present my results. Consequentely, my data have not been published but just the Fitz Maurice's results have been displayed as they were mine. I take the total responsibility about this oversight. The Department of Neurology, the Division of Neurosurgery and the Post Graduation program of the University of São Paulo and their personnel have no responsibility for this inaccuracy, as this article was designed and developed in other institution.

I would like to convey my regrets and apologies about this inopportune misunderstanding. Should I had been more meticulous in my revision of the documents before sending them and when I received the proofs, it would have not occurred. The Stroke paper was the initial inspiration for my work and it was actually used as reference that I now would like to include. I present a new table displaying my actual data and revision of the text to replace that that was portrayed before.
Replace Table 1 for the following:

Table 1. Some data from the patients according to presence of statin use before $\mathrm{ICH}$.

\begin{tabular}{lccc} 
Characteristic & Statin $n=20(24 \%)$ & No statin $n=63(76 \%)$ & $P$ \\
\hline Median age (SD) & $68(8.2)$ & $69(7.6)$ & 0.73 \\
GCS (variation) & $11(6-15)$ & $12(6-15)$ & 0.89 \\
GOS 4 or 5 (90-day & $32 \%$ & $36 \%$ & 0.79 \\
independence) & $41 \%$ & $47 \%$ & 0.82 \\
90-day mortality &
\end{tabular}

In the sentence:

"We calculated that a trial of statins to improve ...

Change to:

FitzMaurice calculated that a trial of statins to improve 90-day outcome should include 1026 subjects (randomized 1:1 to treat with statin or placebo), for it to get $90 \%$ power to detect an OR $>1.24$, for independent status in the statin arm18.

\section{In the sentence:}

"Statins were used ...

Change to:

Were statin users 20/83 (24\%) patients before the ICH. There was no effect from pre-ICH statin use on the functional independence rates $(32 \%$ versus $36 \%, \mathrm{P}=0.79$ ) or mortality ( $41 \%$ versus $47 \%, \mathrm{P}=0.82$ ). Medical comorbidities and warfarin use were more common in statin users. The multivariable-adjusted odds ratio for independent status in pre-ICH statin users was 1.03 (95\% CI: 0.71 to $2.21, \mathrm{P}=0.71$ ).

Include a new reference:

18. FitzMaurice E, Wendell L, Snider R, et al. Effect of Statins on Intracerebral Hemorrhage Outcome and Recurrence. Stroke 2008;39:2151-2154.

Best regards,

Flávio Ramalho Romero 